\title{
OBITUARY
}

\section{RANSOM PicKaRd}

Ransom Pickard, C.B., C.M.G., M.D., M.S., Lond., F.R.C.S., D.P.H., who died on February 9, 1953, at the age of 85 , graduated at Bart's in 1889, and after holding house appointments there and taking the higher qualifications went to Moorfields. He settled in Exeter in the early ' 90 s, and carried on a general practice there. On the formation of the Territorial Army he was largely instrumental in raising the 1st Wessex Field Ambulance and in 1914 he went to France with a regular division; he was soon appointed a C.M.G., and later became A.D.M.S. of the 48th division. For his work in Germany after the armistice he was made a C.B.

On his return to Exeter he began to specialize in ophthalmology. Having early learnt to regard his patients as an entity and not to pay sole regard to the narrow limits of the eye, he was ready to tackle any general operation, and aural surgery particularly interested him. He was appointed Surgeon to the West of England Eye Infirmary (founded the year after Moorfields), and served there with skill and devotion until his retirement. Always ready to learn, he was one of the first to undertake trephining, and when the slit lamp was introduced he went to Vienna to study its uses. Throughout his career he made an estimation and drawing of the size and depth of the cup in every patient, and this led him to investigate the subject of cavernous atrophy and its relation to glaucoma, on which he wrote several papers. His remarks in discussions at the meetings of the local Medico-Chirurgical Society showed his wide knowledge of general medicine and surgery. He was particularly proud of being elected President of the Ophthalmic Section of the Royal Society of Medicine, an honour which rarely went to a provincial surgeon.

Ransom Pickard made an active contribution to each phase of life in which he took part. He held every office open to a layman in the Methodist connexion; he was elected mayor of Exeter in 1927; and he was a Vice-President of the University College of the South-West. His leisure interests were equally numerous and enthusiastic. He was a member of the Alpine Club, a Vice-President of the Exeter Drama League, and Past President of both the Devonshire Association and the Devon Archaeological and Exploration Society. He would take long walks on Saturdays whatever the weather, and return with his pockets full of specimens. To converse with him was to learn much from his deep and various knowledge. He leaves a widow who shared his many interests and was a great help and support to him in all of them. 